\section{Light-emitting Diodes Can Replace High-pressure Sodium Lighting for Cut Gerbera Production}

\author{
Dave Llewellyn, Katherine Schiestel, and Youbin Zheng ${ }^{1}$ \\ School of Environmental Sciences, University of Guelph, 50 Stone Road East, \\ Guelph, Ontario, N1G 2W1, Canada
}

Additional index words. supplemental lighting, cut flower yield, flower quality, Gerbera jamesonii, PAR, DLI, vase life

\begin{abstract}
A greenhouse study was undertaken to investigate whether light-emitting diode (LED) technology can be used to replace high-pressure sodium (HPS) lighting for cut gerbera production during Canada's traditional supplemental lighting (SL) season (November to March). The study was carried out at the University of Guelph's research greenhouse, using concurrent replications of SL treatments within the same growing environment. LED (85\% red, $15 \%$ blue) and HPS treatment plots were set up to provide equal amounts of supplemental photosynthetically active radiation $(P A R)$ at bench level. This setup was used to assess the production of three cultivars of cut gerbera (Gerbera jamesonii H. Bolus ex Hook.f): Acapulco, Heatwave, and Terra Saffier. There were no treatment differences in SL intensity, with average SL photosynthetic photon flux density (PPFD) and daily light integral (DLI) of $55.9 \mu \mathrm{mol} \cdot \mathrm{m}^{-2} \cdot \mathrm{s}^{-1}$ and $2.3 \mathrm{~mol} \cdot \mathrm{m}^{-2} \cdot \mathrm{d}^{-1}$, respectively. Flowers harvested from the LED treatment had a $1.9 \%$ larger flower diameter in 'Acapulco'; 4.2\% shorter and 3.8\% longer stems in 'Heatwave' and 'Terra Saffier', respectively; and 7.7\% and $8.6 \%$ higher fresh weights for 'Acapulco' and 'Terra Saffier', respectively, compared with flowers harvested from the HPS treatment. There were no differences in accumulated total or marketable flower harvests for any of the cultivars. The vase life of 'Acapulco' flowers grown under the LED treatment was $2.7 \mathrm{~d}$ longer than those grown under the HPS treatment, but there were no SL treatment effects on water uptake for any of the cultivars during the vase life trials. There were no SL treatment effects on specific leaf area for any of the cultivars. There were only minimal treatment differences in leaf, soil, and air temperatures. Cut gerbera crops grown with under LED SL had equivalent or better production and crop quality metrics compared with crops grown under HPS SL.
\end{abstract}

In Canada, as in other northern regions, there is not enough natural light for production of many greenhouse commodities during the darker months of the year (i.e., October through February). In these regions, it is necessary for growers of year-round commodities, such as cut gerbera, to use SL to meet their crops' economic minimum lighting requirements. Until recently, the only viable options for SL were highintensity discharge (HID) systems such as HPS lamps. LED technology has improved significantly in recent years, with numerous proven horticultural applications in assimilation (both as SL in greenhouses and as sole-source lighting in growth chambers), photoperiodic, and photomorphogenic lighting (Nelson and Bugbee, 2014; Lopez and Runkle, 2017; Mitchell et al., 2015; Morrow, 2008). LEDs offer the promise of providing

Received for publication 5 June 2018. Accepted for publication 29 Oct. 2018.

This work was financially supported by the International Cut Flower Growers Association and the Joseph H. Hill Memorial Foundation, Inc.; LumiGrow, Inc. supplied the LED lighting fixtures. Plant materials were donated by Rosa Flora Ltd. ${ }^{1}$ Corresponding author. E-mail: yzheng@uoguelph.ca. energy-efficient, wavelength-specific light in long-lasting fixtures (i.e., $>50,000 \mathrm{~h}$ ). Owing to their unique ability to modify the intensity of individual wavebands of light, LED fixtures can be customized to provide varying spectral recipes, potentially increasing quantum efficiency as well as providing greater plasticity for photoperiod and photomorphological control within a single fixture (Bourget, 2008). Morrow (2008), Pinho et al. (2012) and Currey and Lopez (2013) discussed many relevant horticultural considerations of both HPS and LED technologies.

Many commercially available horticultural LED systems are marketed as a direct replacement for conventional overhead HID greenhouse lighting systems. LED systems are often marketed as requiring $30 \%$ to $60 \%$ less electricity as HID systems to elicit the same photosynthetic effect on a crop. This is due to potentially higher efficacy (i.e., efficiency of converting electricity into light) and sole production of targeted wavelengths of blue (B, 400 to $500 \mathrm{~nm}$ ) and red (R, 600 to $700 \mathrm{~nm}$ ) light that closely match the maximum absorption bands for chlorophyll radiation generated by HID systems falls in the green $(\mathrm{G}, 500$ to $600 \mathrm{~nm})$ region or outside (McCree, 1972). Conversely, much of the of the $P A R$ region altogether (Bergstrand et al., 2016). Therefore, LED-generated $P A R$ may be more efficiently used in many horticultural production scenarios.

Most of the greenhouse-based LED scientific research has, thus far, focused on edible (Dueck et al., 2012; Gomez et al., 2013; Hernandez and Kubota, 2015; Martineau et al., 2012; Poel and Runkle, 2017) and potted floriculture commodities (Currey and Lopez, 2013; Poel and Runkle, 2017; Randall and Lopez, 2014). Many of these studies are over short time periods, either investigating a fast-growing crop (e.g., lettuce) or young plants (e.g., seedling development). Typically, these studies use consecutive replication strategies (i.e., treatments replicated over time), which can result in vastly different natural lighting conditions between replications. Moreover, many studies appear to have relied on fixed experimental plot locations for their treatments (i.e., treatment locations are not randomized between replications), which may not give proper consideration to varied environmental conditions that can occur within a greenhouse environment.

A largely untested application for horticultural LEDs is in the production of highvalue cut flowers, where they could be used for assimilation, photoperiod, and photomorphological control depending on the crop, geographic region, and the time of year. The objective of this study was to determine whether LED SL can be used to replace HPS SL in cut gerbera production during the normal SL season in Ontario, Canada, by comparing harvest and postharvest metrics of crops growing under equivalent supplemental PPFD $\left(\mu \mathrm{mol} \cdot \mathrm{m}^{-2} \cdot \mathrm{s}^{-1}\right)$ in a concurrently replicated greenhouse trial.

\section{Materials and Methods}

Location, trial greenhouse description, and bench orientation. The study took place over 19 weeks at the University of Guelph in Ontario, Canada (lat. $43.55^{\circ} \mathrm{N}$, long. $80.25^{\circ} \mathrm{W}$ ) beginning on 1 Nov. 2013 and ending on 12 Mar. 2014. The study was set up in two adjacent glass greenhouse compartments located in a single-span wing of a research greenhouse facility. Each $52-\mathrm{m}^{2}$, square compartment measured $3.7 \mathrm{~m}$ from floor to gutter and $6.1 \mathrm{~m}$ from floor to peak. Each compartment contained four $4.6 \times 1.0 \mathrm{~m}$ parallel benches $(0.8 \mathrm{~m}$ high), with $0.6 \mathrm{~m}$ spacing between benches. The long sides of the benches were positioned in the east-west direction. Each bench was fitted with retractable blackout curtains (originally designed for doing photoperiod control experiments) that extended $1.78 \mathrm{~m}$ above the benches. These side curtains were lowered $0.46 \mathrm{~m}$ and fixed in place such that blackout curtains surrounded each plot from 1.32 to $1.78 \mathrm{~m}$ above the benches, which was sufficient to eliminate spillover of SL from adjacent plots.

Environmental management. The greenhouse environmental parameters were set at similar levels to those at local commercial cut 
gerbera producers: daytime (i.e., during the supplemental photoperiod) and nighttime temperature set points were 21.0 and $16.0{ }^{\circ} \mathrm{C}$, respectively the relative humidity (RH) target was $70 \%$ and was maintained using aerial foggers located at gutter level. Temperature and RH sensors (HOBO U12013; Onset Computer Corporation, Bourne, MA) were located at canopy level in the center of each bench and logged temperature and humidity every $120 \mathrm{~s}$ throughout the study.

Lighting treatments. Each bench had three fixtures of either HPS or LED lights positioned above the benches to provide identical mean PPFD at bench level, distributed as uniformly as practical. The HPS fixtures comprised $400-\mathrm{W}$ ballasts with BETA reflectors (PL2000; PL Lights, Beamsville, ON, Canada) and Lucalox lamps (LU400; GE Lighting Inc., Cleveland, OH). The LED fixtures were Pro 325 (Lumigrow, Novato, CA), whose fan-cooled LED arrays consisted of a combination of blue (B), red (R), and white (W) LEDs. The W LEDs, which are present to facilitate crop viewing, were not used in this study. Peak wavelengths for B and $\mathrm{R}$ were $440 \mathrm{~nm}$ and $660 \mathrm{~nm}$, respectively, and full width at half maximum values were $\approx 20 \mathrm{~nm}$ for both colors. Fixture-mounted controllers allowed for the independent adjustment of the intensity of the $B$ and $R$ wavelength channels. Relative spectral intensity of the HPS and LED SL treatments are shown in Fig. 1.

The lighting treatments were organized in a randomized complete block design with four replicates. Using two identical, adjacent greenhouse compartments, the treatments were blocked across bench positioning relative to the south-facing wall. The lights were set to run daily from $11.5 \mathrm{~h}$ before dusk to dusk (i.e., 11.5-h supplemental photoperiod, ending daily at the end of the natural photoperiod).

The target for bench-level supplemental PPFD was $55 \mu \mathrm{mol} \cdot \mathrm{m}^{-2} \cdot \mathrm{s}^{-1}$, to match SL intensities measured in a local commercial cut gerbera greenhouse. Fixture positioning and determination of SL uniformity distribution patterns were done in each plot, at night, using a USB2000 + spectrometer with a $400-\mu \mathrm{m}$ diameter ultraviolet-VIS optical fiber with a CC-3 cosine corrector (Ocean Optics,

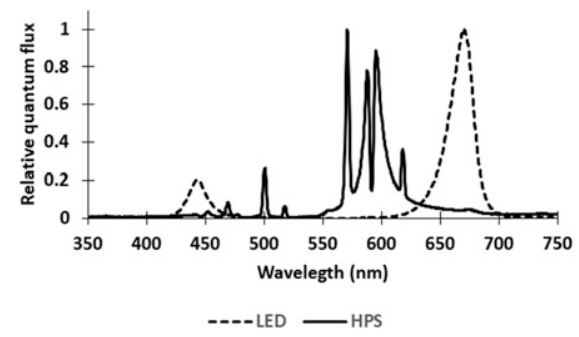

Fig. 1. Relative quantum flux of the high-pressure sodium (HPS; solid line) and light-emitting diode (LED; dotted line) supplemental lighting treatments over the photosynthetically active radiation spectral range (i.e., 400 to $700 \mathrm{~nm}$ ).
Dunedin, FL), which was calibrated for absolute irradiance between 350 and $800 \mathrm{~nm}$. The spectrometer was tethered to a laptop running the PARSpec subroutine within the SpectraSuite (Ocean Optics) software package. PPFD measurements were taken at $0.25 \mathrm{~m}$ above the bench (i.e., at canopy level) at 15 locations on each bench, on a uniformly spaced $3 \times 5$ grid. The light fixtures were hung such that the bottoms of the fixtures were 1.5 and $1.7 \mathrm{~m}$ above the benchtop for the HPS and LED fixtures, respectively. The brightness of the $\mathrm{B}$ and $R$ channels on all LED fixtures were set to 8 (out of 10) while the W LEDs were turned off. This provided a spectral output with a targeted photon flux ratio of B15:R85. The average $( \pm \mathrm{SE})$ SL PPFD was $55.9 \pm 0.47$ $\mu \mathrm{mol} \cdot \mathrm{m}^{-2} \cdot \mathrm{s}^{-1}$, with no differences between treatments (Table 1). With an 11.5-h photoperiod, the SL daily light integral (DLI) was $2.3 \mathrm{~mol} \cdot \mathrm{m}^{-2} \cdot \mathrm{d}^{-1}$.

Sunlight-calibrated quantum sensors (SQ110; Apogee Instruments Inc., Logan, UT), located just above canopy level in the geometric center of each plot and connected to U12-HOBO dataloggers (Onset Computer Corporation), were used to monitor croplevel PPFD at 120-s intervals. Before the start of the trial, measurements were taken under SL in the absence of natural light (i.e., at night) to determine the offset in daytime PPFD measurements arising from the sensors' disparate responses to the different spectra of the SL. These correction factors were then applied to (i.e., subtracted from) logged PPFD data during each SL photoperiod before calculating canopy-level DLIs from natural sunlight. Average weekly canopy-level natural DLI ranged from 1.4 to $4.8 \mathrm{~mol} \cdot \mathrm{m}^{-2} \cdot \mathrm{d}^{-1}$ with an overall average of $2.8 \mathrm{~mol} \cdot \mathrm{m}^{-2} \cdot \mathrm{d}^{-1}$ (Fig. 2). Combined with $\mathrm{SL}$, the average canopy-level total DLI was $5.1 \mathrm{~mol} \cdot \mathrm{m}^{-2} \cdot \mathrm{d}^{-1}$.

Plant distribution and cultural management. Three cut gerbera (Gerbera jamesonii H. Bolus ex Hook.f) cultivars were used for this trial: 'Acapulco' (standard), 'Heatwave' (standard), and 'Terra Saffier' (miniature). Plants were sourced from a local, commercial production greenhouse and were all of similar size and maturity (i.e., had already been producing marketable flowers for 3 to 4 months). Flower stems longer than $3 \mathrm{~cm}$ were removed at the beginning of the study. Each bench had seven pots (19 $\mathrm{cm}$ diameter $\times 19 \mathrm{~cm}$ tall $)$ of each cultivar, spaced evenly in two rows of 11 pots. The cultivars were arranged in an alternating pattern (such that every third plant was a common cultivar), with the starting positions of each plant randomized. There was one empty position (i.e., spare irrigation dripper) on each bench which was used to monitor irrigation water quantity and quality. The vacant position on each bench also simplified the process of moving pot locations,

Table 1. Uniformity distribution of supplemental photosynthetic photon flux density (PPFD) measured (at night) in both high-pressure sodium (HPS) and light-emitting diode (LED) plots.

\begin{tabular}{|c|c|c|c|c|c|c|}
\hline \multirow[b]{3}{*}{ Block } & \multicolumn{6}{|c|}{ PPFD $\left(\mu \mathrm{mol} \cdot \mathrm{m}^{-2} \cdot \mathrm{s}^{-1}\right)$} \\
\hline & \multicolumn{3}{|c|}{ HPS } & \multicolumn{3}{|c|}{ LED } \\
\hline & $\overline{\operatorname{Max}}$ & Min & Mean $^{z}$ & $\overline{M a x}$ & Min & Mean \\
\hline$\overline{\mathrm{A}}$ & 69.0 & 35.4 & $55.5 \pm 2.99$ & 72.4 & 33.7 & $55.0 \pm 4.15$ \\
\hline B & 70.3 & 31.5 & $53.8 \pm 3.61$ & 72.6 & 34.8 & $56.3 \pm 3.76$ \\
\hline $\mathrm{C}$ & 72.3 & 35.6 & $56.7 \pm 3.16$ & 78.4 & 34.8 & $58.4 \pm 4.55$ \\
\hline $\mathrm{D}$ & 77.5 & 34.7 & $55.4 \pm 4.12$ & 76.7 & 34.5 & $56.2 \pm 4.21$ \\
\hline
\end{tabular}

${ }^{\mathrm{z}}$ Means are $\pm \operatorname{SE}(\mathrm{n}=15)$.

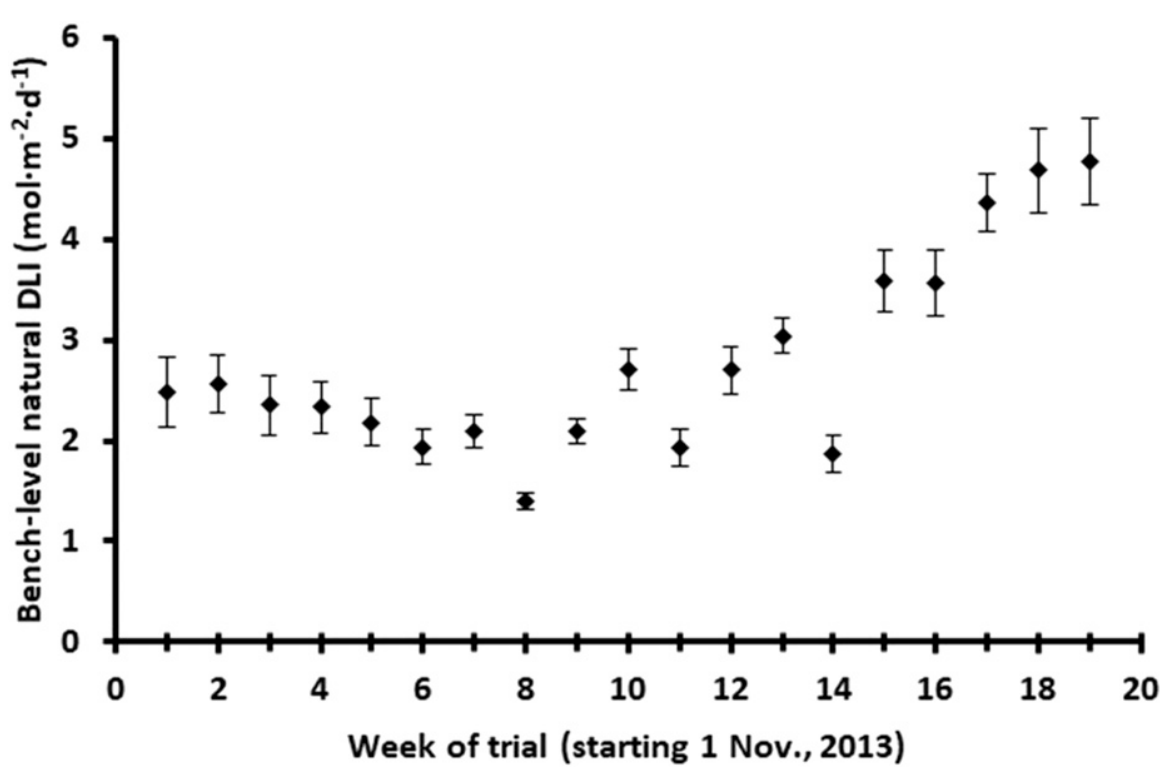

Fig. 2. Weekly mean natural daily light integral (DLI) at bench-level throughout the 19-wk trial. The overall mean natural DLI at bench level was $2.8 \pm 0.98 \mathrm{~mol} \cdot \mathrm{m}^{-2} \cdot \mathrm{d}^{-1}($ mean $\pm \mathrm{SD}, \mathrm{n}=19)$. 
which was done weekly by shifting each plant one position in the clockwise direction, to normalize the growing environment for each plant throughout the trial.

Plants were fertigated via pressurecompensated drip irrigation lines $\left(4 \mathrm{~L} \cdot \mathrm{h}^{-1}\right)$, using $20 \mathrm{~N}-3.5 \mathrm{P}-16.6 \mathrm{~K}$ All Purpose watersoluble fertilizer (250 ppm N, pH 5.5; Plant Products Co. Ltd., Brampton, ON, Canada) with temporary substitutions of clear well water $[\mathrm{pH} 7.9$ and electrical conductivity (EC) $\left.1005 \mu \mathrm{S} \cdot \mathrm{cm}^{-1}\right]$, when necessary, to maintain an approximate leachate $\mathrm{pH}$ of 5.5 and EC of $2500 \mu \mathrm{S} \cdot \mathrm{cm}^{-1}$. Pulse irrigation occurred every second day at 0915 and 1315 HR for $180 \mathrm{~s}$ each time, with the goal of producing $10 \%$ to $25 \%$ leachate. Hand watering was used to supplement the drip irrigation, when needed. The $\mathrm{pH}$ and $\mathrm{EC}$ of irrigation water and leachate were monitored weekly using a portable meter (Oakton PC 300; Oakton Instruments, Vernon Hills, IL).

Cut flower harvesting and quality metrics. Flowers were deemed harvestable once they developed one complete ring of matured anthers. Flowers were harvested three times per week, during which times fresh weight, flower diameter (measured petal tip to petal tip across the widest part of the flower), and stem length (measured from the heel to the base of the flower) were measured on each harvested flower. Flower quality was classified subjectively as either marketable or unmarketable according to the severity of malformations and pest damage. Marketable flowers had no visual signs of mutation or disease, and the flower head was not malformed or any malformations were slight and not easily noticed. Unmarketable flowers were visually unattractive with petal malformations or discoloration, or visual signs of disease present in the center of the flower or on the petals. Flowers were considered unmarketable if they met one or more of these criteria.

Vase life. Vase life trials were performed by collecting one marketable flower from each cultivar in each plot during flower harvests on 17 and 20 Jan. 2014 (trial 1), and again on 12, 14, and 18 Feb. 2014 (trial 2 ). Heels were removed from the stems by making a lateral cut $2 \mathrm{~cm}$ from the bottom of the stem, after which the stems were placed in sterilized graduated cylinders containing $100 \mathrm{~mL}$ of deionized water. The vase life trials occurred inside a windowless room that was lit constantly with fluorescent lamps at $5 \mu \mathrm{mol} \cdot \mathrm{m}^{-2} \cdot \mathrm{s}^{-1}$ and maintained at a constant temperature of $23.0^{\circ} \mathrm{C}$ and an average $\mathrm{RH}$ of $18.6 \%$ (a low but not uncommon humidity level in occupied environments during Canadian winters). Flowers were considered to have reached the end of their vase life when any of the following symptoms developed: petal wilting (flaccid petals), petal abscission, petal discoloration, and/or development of a bent neck (i.e., $90^{\circ}$ bend at the peduncle region; Robinson et al., 2009). Flowers were evaluated daily for the onset of the preceding symptoms. To quantify water consumption, remaining water volumes in the graduated cylinders were measured after $7 \mathrm{~d}$.

Specific leaf area measurement. On 5 Mar. 2014, three young, fully expanded leaves were harvested per plant, on three plants per cultivar per plot. Petioles and central veins were removed, and the combined area of the leaf tissues sampled from each plant was measured using a leaf area meter (LI-COR 3100; LI-COR Biosciences, Lincoln, NE). Leaves were oven-dried at $65{ }^{\circ} \mathrm{C}$ until the weights were constant, then dry weights were measured. Specific leaf area (SLA) was calculated as SLA = leaf area/dry weight.

Leaf, growing substrate, and air temperatures. Leaf temperature was measured on one plant of each cultivar located near the middle of the two centrally located plots (i.e., under each of the lighting treatments) in one of the greenhouse sections. A small (9.5 mm long and $2.0 \mathrm{~mm}$ diameter) thermistor (MA100GG103A NTC; GE, Lewistown, PA) was attached to the underside of the youngest fully expanded leaf of each tested plant using Fisherbrand green paper labeling tape (1590120C, Fisher Scientific, Ottawa, ON, Canada). Leaf temperature was logged at 120-s intervals for $4 \mathrm{~d}$ (15 to 18 Feb. 2014) using U12-HOBO data loggers (Onset Computer Corporation). Daily mean leaf temperatures were calculated by averaging the logged data from each thermistor for the following time periods: day (1000 to $1600 \mathrm{HR}$ ) and night (0000 to $0600 \mathrm{HR}$ ).

Supplementary to the preceding leaf temperature measurements, 'Acapulco' plants from the same plot locations were selected to monitor air, growing substrate, and leaf temperatures concurrently, using the same sensors and loggers. The growing substrate temperature probes were placed half of the distance between the edge of the pot and the center of the plant crown, on the opposite side of the pot as the irrigation dripper and about $10 \mathrm{~cm}$ deep. The air-temperature probes were shielded from direct radiation by placing them under white polystyrene shields (Great Value disposable soup bowls; Walmart Canada, ON, Canada) and placed $\approx 20 \mathrm{~cm}$ above the plant canopy on bamboo stakes. The leaf-temperature probes were attached using the method described above. Temperatures were recorded (120-s intervals) between 1100 and $1800 \mathrm{HR}$ on 19 Feb. 2014.

Statistical analysis. Vegetative and flower production metrics were analyzed using JMP (version 13; SAS Institute Inc., Cary, NC). In addition, analyses of SL uniformity, total DLI, temperatures (leaf, growing substrate, and air), and SLA were performed with Prism (version 5.03; GraphPad Software Inc., La Jolla, CA), using two-tailed $t$ tests and a significance level of $P<0.05$. Least squares analysis models were used for: flower diameter, stem length, and fresh weight of all marketable flowers; accumulated total and marketable flowers harvested per plant; and vase life and postharvest water usage. When differences were found between means, these differences were evaluated using Tukey's honestly significant difference test, with a significance level of $P<0.05$.

\section{Results}

Lighting treatments. Summary data on the supplemental light levels within each plot (Table 1) indicate the mean PPFD and uniformity distribution were similar for each plot. A $t$ test (data not shown) comparing supplemental PPFD within each treatment $(\mathrm{n}=60)$ indicated no treatment differences $(P=0.26)$ and an overall mean supplemental PPFD of $55.9 \pm 0.47 \mu \mathrm{mol} \cdot \mathrm{m}^{-2} \cdot \mathrm{s}^{-1}$.

Cut-flower yield and quality metrics. 'Terra Saffier' flowers under the HPS treatment produced about $15 \%$ more flowers than under the LED treatment. However, both 'Heatwave' and 'Terra Saffier' had higher percentages of marketable flowers under the LED treatment (Table 2), resulting in higher total numbers of marketable flowers. Flowers under the LED vs. HPS treatment had a $1.9 \%$ larger flower diameter in 'Acapulco', 4.2\% shorter and 3.8\% longer stems in 'Heatwave' and 'Terra Saffier', respectively, and 7.7\% and $8.6 \%$ higher fresh weights for 'Acapulco' and 'Terra Saffier', respectively (Table 2).

Vase life. The only treatment effect on postharvest quality was a $2.7-d$ increase in vase life for 'Acapulco' in the LED treatment (Table 2). There were no treatment effects for any of the cultivars for water uptake during the first $7 \mathrm{~d}$ postharvest.

Specific leaf area. There were no treatment effects on SLA for any of the cultivars (Table 2).

Leaf, growing substrate, and air temperatures. The daytime air temperature in the HPS treatment was $0.7^{\circ} \mathrm{C}$ warmer than the LED treatment, but there were no treatment effects on daytime growing substrate temperature (Table 3 ). The increased daytime air temperature in the HPS treatment did not, however, result in higher daytime leaf tissue temperatures (Table 4 ) in any of the cultivars. The night leaf temperature in the HPS treatment was slightly $\left(\approx 0.1{ }^{\circ} \mathrm{C}\right)$ warmer than that in the LED treatment.

\section{Discussion}

Weekly flower production rates ranged from 0.41 to 0.75 stems/plant, depending on the cultivar. This was consistent with rates reported by local growers (personal communication) during the darker months and also other greenhouse cut gerbera production research. Sirin (2011) reported weekly flower stem production rates of 0.24 to 0.67 stems/ plant during a 58 -week production cycle in Turkey, and Tsirogiannis et al. (2010) reported 0.56 to 0.65 stems/plant during late spring/early summer production in Greece. Both of these trials occurred at lower latitudes $\left(<40^{\circ} \mathrm{N}\right)$ and times of the year when natural light levels are typically higher. Therefore, although the natural and supplemental DLIs may have been relatively low in 
Table 2. Flower harvest and postharvest metrics and specific leaf area of 'Acapulco', 'Heatwave', and 'Terra Saffier' cut gerbera plants grown under high-pressure sodium (HPS) and light-emitting diode (LED) supplemental lighting (SL) treatments from 1 Nov. 2013 to 12 Mar. 2014.

\begin{tabular}{lcccc}
\hline & & Acapulco & Heatwave & Terra Saffier \\
\hline Total no. of harvested flowers per plant & HPS & $7.67 \pm 0.41^{\mathrm{y}}$ & $8.39 \pm 0.41$ & $14.3 \pm 0.63$ \\
& LED & $7.71 \pm 0.47$ & $9.14 \pm 0.51$ & $12.2 \pm 0.59$ \\
& $P^{x}$ & 0.95 & 0.19 & 0.016 \\
Percent marketable ${ }^{z}$ & HPS & $91.2 \pm 3.1$ & $51.2 \pm 4.0$ & $65.4 \pm 4.1$ \\
& LED & $96.8 \pm 1.1$ & $67.2 \pm 3.3$ & $88.4 \pm 2.7$ \\
Flower diameter $(\mathrm{cm})$ & $P$ & 0.064 & 0.001 & $<0.0001$ \\
& HPS & $10.2 \pm 0.04$ & $9.8 \pm 0.05$ & $7.2 \pm 0.03$ \\
& LED & $10.4 \pm 0.04$ & $9.8 \pm 0.04$ & $7.2 \pm 0.02$ \\
Stem length $(\mathrm{cm})$ & $P$ & 0.0015 & 0.66 & 0.55 \\
& HPS & $47.3 \pm 0.44$ & $56.0 \pm 0.58$ & $51.9 \pm 0.40$ \\
& LED & $48.0 \pm 0.45$ & $54.2 \pm 0.43$ & $54.2 \pm 0.28$ \\
Fresh weight $(\mathrm{g})$ & $P$ & 0.26 & 0.01 & $<0.0001$ \\
& HPS & $28.7 \pm 0.40$ & $30.0 \pm 0.50$ & $20.8 \pm 0.23$ \\
& LED & $30.4 \pm 0.41$ & $29.4 \pm 0.39$ & $22.7 \pm 0.18$ \\
Vase life $(\mathrm{d})$ & $P$ & 0.0032 & 0.3002 & $<0.0001$ \\
& HPS & $11.0 \pm 0.71$ & $9.8 \pm 0.37$ & $12.8 \pm 1.4$ \\
& LED & $13.4 \pm 0.60$ & $10.3 \pm 0.73$ & $11.1 \pm 0.77$ \\
Water uptake $\left(\mathrm{mL} \cdot \mathrm{wk}^{-1}\right)$ & $P$ & 0.02 & 0.55 & 0.33 \\
& HPS & $54.5 \pm 3.62$ & $44.0 \pm 3.47$ & $62.9 \pm 4.03$ \\
Specific leaf area ${ }^{\mathrm{w}}\left(\mathrm{cm}^{2} \cdot \mathrm{g}^{-1}\right)$ & LED & $51.5 \pm 1.63$ & $45.4 \pm 0.3 .18$ & $62.8 \pm 1.79$ \\
& HPS & $140 \pm 10$ & $205 \pm 5.2$ & 0.98 \\
& LED & $143 \pm 8.2$ & $206 \pm 6.3$ & $179 \pm 6.7$ \\
& $P$ & 0.8 & 0.83 & 0.9 \\
\hline
\end{tabular}

${ }^{\mathrm{z}}$ Flower quality was classified subjectively as either marketable or unmarketable according to the severity of malformations and pest and disease damage.

${ }^{\mathrm{y}}$ Data are treatment means $\pm \mathrm{SE}$. For number of flowers per plant and percent marketable, $\mathrm{n}=28$. For flower diameter, stem length, and fresh weight, $\mathrm{n}=$ the total number of marketable flowers for each respective 'cultivar $\times$ SL treatment combination' (presented at the top of the table). For vase life and water uptake, $\mathrm{n}=$ 8. For specific leaf area, $\mathrm{n}=24$.

${ }^{\mathrm{x}} P=P$ value of the difference between means, compared using two-tailed unpaired $t$ tests. The Welsh's correction was used for flower diameter, stem length, and fresh weight data to account for unequal sample numbers.

${ }^{\mathrm{w}}$ For specific leaf area, three young fully expanded leaves were harvested per plant and combined, excluding petioles and central veins, for three plants per cultivar per plot.

Table 3. Representative daytime growing substrate and air temperatures measured on single plants ('Acapulco') in the center of two adjacent highpressure sodium (HPS) and light-emitting diode (LED) plots (the two central benches in one of the greenhouse compartments), on 120-s intervals between 1100 and $1800 \mathrm{HR}$ on 19 Feb. 2014.

\begin{tabular}{lccc}
\hline & \multicolumn{3}{c}{ Temperature $\left({ }^{\circ} \mathrm{C}\right)^{\mathrm{z}}$} \\
\cline { 2 - 4 } & HPS & LED & $P^{\mathrm{y}}$ \\
\hline $\begin{array}{l}\text { Growing } \\
\text { substrate }\end{array}$ & $19.9 \pm 0.09$ & $19.8 \pm 0.09$ & 0.45 \\
Air & $21.5 \pm 0.06$ & $20.8 \pm 0.06$ & $<0.001$ \\
\hline
\end{tabular}

${ }^{\mathrm{z}}$ Data are means \pm SE $(\mathrm{n}=210)$

${ }^{\mathrm{y}} P=P$ value of the difference between means, compared using paired two-tailed $t$ tests.

Table 4. Average day and night leaf temperatures of cut gerbera plants grown under high-pressure sodium (HPS) and light-emitting diode (LED) treatments, logged at 120 -s intervals from 15 to 18 Feb. 2014. Daily mean leaf temperatures were calculated by averaging the logged data from each thermistor for the following time periods: day (1000 to $1600 \mathrm{HR}$ ) and night (0000 to $0600 \mathrm{HR}$ ).

\begin{tabular}{lccr}
\hline & \multicolumn{3}{c}{ Leaf temp $\left({ }^{\circ} \mathrm{C}\right)^{\mathrm{z}}$} \\
\cline { 2 - 4 } & HPS & LED & \multicolumn{1}{c}{$P^{\mathrm{y}}$} \\
\hline Night & $15.1 \pm 0.04$ & $15.0 \pm 0.02$ & $<0.001$ \\
Day & $20.4 \pm 0.20$ & $20.9 \pm 0.16$ & 0.087 \\
\hline
\end{tabular}

${ }^{\mathrm{z}}$ Data are means (averages of three sensors, one per cultivar, collected on 120-s intervals for 4 consecutive days $) \pm \operatorname{SE}(\mathrm{n}=12)$.

${ }^{\mathrm{y}} P=P$ value of the difference between means, compared using two-tailed $t$ tests. the HPS treatment when they compared the growth of cucumber transplants grown under HPS or monochromatic R or B LEDs at a canopy-level PPFD of about $57 \mu \mathrm{mol} \cdot \mathrm{m}^{-2} \cdot \mathrm{s}^{-1}$ with an 18 -h photoperiod (i.e., $3.7 \mathrm{~mol} \cdot \mathrm{m}^{-2} \cdot \mathrm{d}^{-1}$ ). They attributed the higher shoot biomass in the HPS treatment to higher air temperatures; however, it is uncertain that the air temperature in the HPS plot was significantly higher than that in the LED plot. Martineau et al. (2012) did not observe any treatment differences between HPS and LED for hydroponic lettuce production, despite having HPS treatments that provided both twice and half the supplemental PPFD as the LED treatment. This may, in part, be due to the relatively low proportion of supplemental to total PPFD, at roughly $20 \%, 10 \%$, and $5 \%$ for the HPS-high, LED, and HPS-low treatments, respectively. Currey and Lopez (2013) reported minor differences between HPS and LED treatments for the production of cuttings of Impatiens, Pelargonium, and Petunia. Randall and Lopez (2014) reported similar or higher seedling quality metrics in Antirrhinum, Catharanthus, Celosia, Impatiens, Pelargonium, Petunia, Tagetes, Salvia, and Viola grown under $5.7 \mathrm{~mol} \cdot \mathrm{m}^{-2} \cdot \mathrm{d}^{-1}$ (accounting for $\approx 40 \%$ to $70 \%$ of total DLI, depending on the natural lighting conditions in their consecutively replicated trial) of supplemental LED vs. HPS, indicating that LEDs could be a suitable replacement for HPS for SL in greenhouse production systems.

Postharvest vase life metrics were similar to those reported by De Silva et al. (2013) and Safa et al. (2012) for solutions without added preservatives. With treatment differences found for only one cultivar in the present study, further studies are required to elucidate the effects that LED SL could have on vase life.

It is a commonly held belief that supplemental HPS lighting increases the canopy temperature relative to supplemental LED lighting, due to inherently higher levels of radiant heat directed from HPS fixtures toward the canopy (Faust and Heins, 1997). Whether added heat is a benefit or a liability depends on the production scenario and environment control strategy, although foliar heating (and thus rapid drying) is often touted as a benefit of HPS lighting technologies vs. LEDs. This trial showed a $0.7{ }^{\circ} \mathrm{C}$ higher daytime air temperature, measured just above canopy level, in the HPS vs. LED treatments. However, the increase in air temperature in the HPS treatment did not carry over to daytime leaf and growing substrate temperatures or alter leaf morphology. Given that the plants were adequately hydrated, it appears that they were sufficiently able to manage the additional heat load (from HPS lighting) through transpiration in the experimental setting of the present study.

\section{Conclusion} $\left(42.7^{\circ} \mathrm{N}\right)$, time of year (for their first replicate), and greenhouse light transmission as the present study. Hernandez and Kubota (2015) found $28 \%$ higher shoot biomass in
The levels of supplemental $P A R$ tested in this trial showed that horticultural LEDs were 
comparable or superior to HPS as SL in terms of typical production and postharvest metrics for greenhouse production of cut gerbera. Although economic factors of the different technologies were not investigated, horticultural LEDs appear to be a viable alternative to HPS as SL for greenhouse production of cut gerbera during the darker months at northern latitudes.

\section{Literature Cited}

Bergstrand, K.-J., L.M. Mortensen, A. Suthaparan, and H.R. Gislerød. 2016. Acclimatisation of greenhouse crops to differing light quality. Scientia Hort. 204:1-7.

Bourget, C.M. 2008. An introduction to lightemitting diodes. HortScience 43:1944-1946.

Currey, C.J. and R.G. Lopez. 2013. Cuttings of Impatiens, Pelargonium, and Petunia propagated under light-emitting diodes and high-pressure sodium lamps have comparable growth, morphology, gas exchange, and post-transplant performance. HortScience 48:428-434.

De Silva, W.A.N.T., J.P. Kirthisinghe, and L.M.H.R. Alwis. 2013. Extending the vase life of gerbera (Gerbera hybrida) cut flowers using chemical preservative solutions. Trop. Agricultural Res. 24:375-379.

Dueck, T.A., J. Janse, B.A. Eveleens, F.L.K. Kempkes, and L.F.M. Marcelis. 2012. Growth of tomatoes under hybrid LED and HPS lighting. Acta Hort. 952:335-342.
Faust, J.E. and R.D. Heins. 1997. Quantifying the influence of high-pressure sodium lighting on shoot-tip temperature. Acta Hort 418:85-92.

Gomez, C., R.C. Morrow, C.M. Bourget, G.D. Massa, and C.A. Mitchell. 2013. Comparison of intracanopy light-emitting diode towers and overhead high-pressure sodium lamps for supplemental lighting of greenhousegrown tomatoes. HortTechnology 23:9398.

Hernandez, R. and C. Kubota. 2015. Physiological, morphological, and energy-use efficiency comparisons of LED and HPS supplemental lighting for cucumber transplant production. HortScience 50:351-357.

Lopez, R. and E.S. Runkle. 2017. Light management in controlled environments. Meister Media Worldwide, Willoughby, $\mathrm{OH}$.

Martineau, V., M. Lefsrud, and M.T. Nanzin. 2012. Comparison of light-emitting diode and highpressure sodium light treatments for hydroponics growth of Boston lettuce. HortScience 47:477-482.

McCree, K.J. 1972. The action spectrum, absorptance and quantum yield of photosynthesis in crop plants. Agr. Meteorol. 9:191-216.

Mitchell, C.A., M.P. Dzakovich, C. Gomez, R. Lopez, J.F. Burr, R. Hernández, C. Kubota, C.J. Currey, Q. Meng, E.S. Runkle, C.M. Bourget, R.C. Morrow, and A.J. Both. 2015. Lightemitting diodes in horticulture. p. 1-87. In: J. Janick (ed.). Horticultural Reviews, Vol. 43. Wiley, New York, NY.
Morrow, R.C. 2008. LED lighting in horticulture. HortScience 43:1947-1950.

Nelson, J.A. and B. Bugbee. 2014. Economic analysis of greenhouse lighting: Light emitting diodes vs. high intensity discharge fixtures. PLoS One 9(6): e99010, doi: 10.1371/journal.pone.0099010.

Pinho, P., K. Jokinen, and L. Halonen. 2012. Horticultural lighting: Present and future challenges. Light. Res. Technol. 44:427-437.

Poel, B.R. and E.S. Runkle. 2017. Seedling growth is similar under supplemental greenhouse lighting from high-pressure sodium lamps or lightemitting diodes. HortScience 52:388-394.

Randall, W. and R.G. Lopez. 2014. Comparison of supplemental lighting from high-pressure sodium lamps and light-emitting diodes during bedding plant seedling production. HortScience 49:589-595.

Robinson, S., T. Graham, M. Dixon, and Y. Zheng. 2009. Aqueous ozone can extend vase-life in cut rose. J. Hort. Sci. Biotechnol. 84:97-101.

Safa, Z., D. Hashemabadi, and B. Kaviani. 2012. Improving the vase life of cut gerbera (Gerbera jamesonii L. cv. 'Balance') flower with silver nano-particles. Eur. J. Expt. Biol. 2:24892492.

Sirin, U. 2011. Effects of different nutrient solution formulations on yield and cut flower quality of gerbera (Gerbera jamesonii) grown in soilless culture system. Afr. J. Agr. Res. 6:4910-4919.

Tsirogiannis, I., N. Katsoulas, and C. Kittas. 2010. Effect of irrigation scheduling on gerbera flower yield and quality. HortScience 45:265270. 